\title{
Implicit Learning is a General Predictor of Professional Development Success and the Achievement of Expert Level
}

\author{
Costrikina I. S. \\ Moscow State University of Psychology \& Education. Russia.
}

\author{
Doi:10.5901/jesr.2013.v3n7p533
}

\begin{abstract}
Searching cognitive predictors of effective professional development need for the HR practice and science cognitive research. This study is directed towards a definition of integration of intellectual abilities as predictors of practical success in different professions. Correlation between the level of psychometric intelligence structures, creativity and implicit learning in different professions: specialists in information technologies, economists, educators had been identified. Hypothesis that performance on implicit learning tasks are related to professional success through different professions and specific patterns of cognitive characteristics are promoted real achievements in different professional sphere were examined. Data analysis was made by statistical software WizWhy, Mathlab.
\end{abstract}

\section{Introduction}

Effective workplace learning, quick entry into professional field and forming of competences, rapidity in qualification growth are required by today's labor market from applicants, young specialists and employees. Searching cognitive predictors of effective professional development is important for HR- practice and science cognitive research.

IQ is traditional predictor of professional achievements in sophisticated forms of activity, in high -technology fields. In some cases, the general intelligence is not sufficient for accurate prediction of achievement, and then adds the creativity, learning, adaptability and other parameters. Which option is the stronger predictor for a specific area of activity?

Hypothesis of this study: the intersection of cognitive function is a predictor of real performance in the forms challenging professional activities. On the other hand, the universal predictor not excluded. Perhaps intelligence works as predictor in some professional field, learning works in the other field, and creativity works in others forms of activity, something else works in other. The special role in predicting professional success may belong to implicit learning.

Appeal to issues of opportunities and mechanisms of increase individual and intellectual potential, intellectual performance, natural and artificial intelligence effectiveness has led to an exponential growth of empirical researches of implicit learning and implicit knowledge. Interest in the implicit cognitive processes has been grown since the work of Arthur Reber and Michael Polanyi publication. This increase is associated with the development of the methodology of the empirical study and formation of specific fields of study of implicit cognitions.

This study addressed to the various cognitive correlations with the implicit learning ability as patterns of properties. These patterns are predictive of success.

\section{Theory, Methodology and Philosophy.}

The implicit learning in the number of implicit cognition is the most mysterious process give to growth intellectual potential and exit for any intellectual system to the next level. For example, social knowledge typically develops in an implicit form and only later become known. The reason for this is the implicit initially - is that it develops in a relatively slow process of induction, in which many different particles of social information are gradually pieced together through statistical learning processes (Cleermans, 2008). The human can take on various forms of knowledge, including abstract declarative knowledge during implicit learning (Cleeremans, Jimenez, 2002; Rey; Goldstein; Perruchet, and others). Acquiring knowledge through implicit learning is critically important for the implementation of activities in various fields, such as the development of speech (Saffran, Newport, Aslin, Tunick, \& Barrueco, 1997), the development of the social context (Lewicki, 1986), the perception of music (Dienes \& Longuet-Higgins, 2004;), perceptual ability and complex perceptual skills (Kiesel, Kunde, Pohl, Bemer, and Hoffmann, 2009). Implicit learning processes are responsible for the practical 
achievements in the intellectual-intensive areas and the expertise of professional development (Gobet \& Charness, 2006; Kostrikina, 2010, etc.).

Studies of implicit learning and implicit knowledge was began as two independent lines, but at the time there was a crossing of these empirical areas, as obtained evidence that the implicit learning process a person can take different forms knowledge, including abstract declarative knowledge is critically important for the implementation of activities in the various areas such as the language development, development understanding of the social context, the perception of music, perceptual competence and complex perceptual skills. Implicit learning processes are responsible for practical achievements in the intellectual-intensive areas and the expertise of professional development. Thus, the individual intellectual efficiency largely depends on the processes implicit training and learning.

Reber A., identified this phenomenon in materials and artificial grammar for the first time and defended it as cognition, necessary for the survival of homo sapiens, as adaptive ability to identify patterns of the environment, not independent of conscious attempts to learn and acquire explicit knowledge on learning, the ability of an alternative intelligence (Reber, 1967, 1993).

System-forming role of the category of consciousness in cognitive processes (Vygotsky, 1994) are not sufficiently represented in both Russian and western cognitive studies. Adaptive, creative, predictive functions as common consciousness and intelligence in cognitive researches are still little. Insufficient light of consciousness is manifested in the dominance of the computer metaphor in its early formulations, although consciousness - is not only process information, but also an experience that is beyond a simple calculation (Chalmers, 2008). Investigation of the processes of implicit learning phenomena integrates cognitive processing, subjective phenomenal experience and metacognitions that allow us to study the mind and intelligence in a variety of functional manifestations.

Little empirical research in cognitive psychology and technical developments, taking into account the definition of consciousness as a system provides the most flexible control and behavior management, while knowledge (cognition) are defined as the most important factor in shaping the content of conscious experience. For research of implicit learning in graded, dynamic perspective need identification philosophical foundations. Learning forms the mind and consciousness and reflects the adaptive assessment of the dynamics of the current situation. The question of how to develop and learning is increasing consciousness complexity remains open. It is therefore necessary philosophical appeal and to further methodological appeal to a special sub-symbol level of consciousness, as a unique phenomenon of the human psyche.

Philosophical community should identify the main methodological aspects of research and modeling of implicit learning, and other implicit cognition with the main aspects of the prevailing psychological science and practice, and practice of creating artificial intelligence. It is the following:

evolutionary aspect is related to the presence of qualitative and irreversible cognitive procedural characteristics to the outcomes of implicit learning intellectual system. For example, the artificial intelligence system with a component of implicit learning is not only a self-learning, but also locally evolving.

dynamic aspect is manifested in the fact that implicit learning, as well as any cognitive process, providing an effective intellectual activity is not static, as well as the variation in the forms and is in a dynamic, process and interval of changing relations with other cognitive processes and meta-cognitions.

resource's aspect is manifested in ensuring of the behavior system effectiveness in emergency situations and explication previously involved cognition, i.e. intellectual resources. A resource can be spent or incremented by realizing the potential that determines the range of productivity. Implicit learning is the process of providing cognitive growth and hence the stability of the system in a changing intellectual or obscure circumstances. Perhaps implicit memory or attention distribution has this feature.

The researching implicit cognitions open new perspective on the relationships between conscious and unconscious processing and on the function of consciousness in cognitive systems. Philosophical conceptualization of human cognitive resource allows integrating the accumulated methodologically empirical cognitive research and paradigmatic diversity measurement of implicit cognition. Cognitive sciences closer to solving the mystery of human evolution and co-evolution of consciousness and unconsciousness throw integrating different theories of knowledge and epistemology directions, general branches of philosophy.

Modern methodological study phenomena of implicit cognitions as mechanisms of growth of intelligence bases on the concepts:

Post-nonclassical science philosophy, priorities interdisciplinary studies the effect of "paradigmatic transplants" and understand science as part of the socio-cultural system that operates with such concepts as social codes and worldview universals; 
- Epistemology implicit knowledge, in which it was introduced the notion of implicit, personal knowledge;

- Philosophy of comprehensive knowledge and the concept of knowing the whole man;

- The theory of the evolution of consciousness and awareness, defining "dynamic calibrated perspective" of consciousness and implicit learning as a mechanism for the development of consciousness;

- The concept of implicit learning as the acquisition is not practical knowledge, pushing the limits of intelligence beyond the practical importance of it;

- The philosophy of artificial intelligence, we denote the value of open meaning of the concept intelligence, covers the basics of modeling intelligence as a process of implicit learning subsymbol level of consciousness;

- The ideology of learning information environment as central to the study of cognition;

- The concept of the hierarchy of processes in the system "consciousness - knowledge - learning";

The modern practice of measuring the cognitive processes in the context of predicting success and professional achievements forms a series of dichotomies in the interpretation of empirical data. These are some of them:

Expressed ability vs. adaptive functioning;

Structure vs. function;

Quantity vs. quality;

Common vs. rare;

Academic vs. social-emotional and practice.

Still open questions:

Can we modify cognitive ability general intelligent or implicit learning, or other? How can we modify implicit learning ability for example?

What are the effects from everyday outcomes of modifying implicit learning? Far-transfer effect, long-term changes are possibility?

General methodological problems persist:

Illusive and difficult to define cognitive abilities

Difficult measurements.

In total, the flow of questions and contradictions is created by the volume of empirical data. Empirical data are waiting for their reflection and restructuring, new empirical researches are waiting for new methodological schemes.

\section{Empirical issue}

This study is directed towards a definition of integration of intellectual abilities as predictors of practical success in different professions. Correlation between the level of psychometric intelligence structures, creativity and implicit learning in different professions representatives with different necessary levels of social activity: information technologies specialists, economists, educators, government servants, had been identified.

Then the hypothesis that performance on implicit learning tasks are related to professional success through different professions and specific patterns of cognitive characteristics are promoted real achievements in different professional sphere were examined in a samples of 560 specialists (age 18-38; information technology specialists, economists, educators, government servants). The experiments on different samples have been being carried out since 2001. Parameters of successful and achievements: High standard of wages, high standard of employment place, successful own business-projects, high category of the government tariff, PHD- degree, expert consulting activity.

Measurements: German intelligence test (Test (1ST), Amthauer, Brocke, Liepmann, \& Beauducel, 1999; Russian modification), Group-Embedded Figures Test (GEFT, Witkin, Oltman, Raskin, Karps), Torrance creativity test (Russian modification), Reber's tasks of artificial grammar (Gebauer and Mackintosh,2007).

Statistical possessing is performed on different groups and for whole participants. Traditional methods such as correlation analysis, dispersion analysis were used. However findings from results of fuzzy logic methods were more interesting and practical. Data structuring allowed finding more strong and universal predictors and systems crossing of cognitions.

According to data analysis correlates between different structures cognitive abilities are different for group which have practical achievements, professional successful and group without practical achievements, professional successful. Same correlation from group "achievements and successful" is consisted of participants from different professional areas: verbal subtest \# 4 and mathematic subtest \#6 (IST, R. Amthauer), $p<0,0000$; originality and perception constructive Activity (Torrance creativity test), $p<0,001$; subtest \#6 (IST, R. Amthauer) and artificial grammar task (Reber's paradigm), $p<0,004$; time of Group-Embedded Figures Test (GEFT, Witkin, Oltman, Raskin, Karps) and artificial 
grammar task, $p<0,0003$.

Correlations demonstrate the structural connectivity components. We are interested in the presence of predictive patterns of cognitive functions. Forecasting problems is solved by different methods. Decision trees and constrained combinatorial sorting, subtractive classification methods may give new possibility for regularity and pattern extracting in multidimensional data. Two instruments were chosen for this research. These WisWhy system and algorithm subtractive clusterization of Mathlab system. Methods of this kind are often used in the economy and marketing prognostic research, technical modeling. For psychology it is rare. WizRule is a data auditing and cleansing tool based on data mining. WizRule automatically reveals all the rules in a given data, and points at the deviations from the discovered rules as suspected errors. We use WizWhy system and WizRule tool as system supporting for diagnostic decisions and search predictors professional development for researches and HR-practice. The following possibilities were most important:

- $\quad$ Finding maximum quantity if-then - rules for a short interval of time;

- WizWhy will determine how the values of one field are affected by the values of other fields-defining the best segmentation of numerical variables;

- Calculating the forecasting power of each attribute;

- Revealing unusual phenomena in data;

- Using the discovered rules for forecasting;

Data analysis throw whole sample allowed identify cognitive ability patterns are predicts practical achievements of different professionals (Table 1).

Table1. The results final analysis of 160 "if-then" rules and trends were extracted by WizWhy system.

\begin{tabular}{|c|c|c|}
\hline \multicolumn{3}{|l|}{ Participants: the young experts and postgraduates } \\
\hline IT-specialists (age 16-28) & Business Managers (age 23-33) & Educators (age 22-34) \\
\hline \multicolumn{3}{|c|}{ The real practical achievements } \\
\hline $\begin{array}{l}\text { Author's softwares, license, patents, PHD- } \\
\text { degree, expert consulting activity. }\end{array}$ & $\begin{array}{l}\text { High standard of wages, high standard } \\
\text { of employment place, successful own } \\
\text { business-projects, consulting activity. }\end{array}$ & $\begin{array}{l}\text { Work place at school gymnasiums, high } \\
\text { category of the government tariff, PHD } \\
\text { degree, own projects. }\end{array}$ \\
\hline \multicolumn{3}{|c|}{$\begin{array}{l}\text { Measures: German intelligence test (Test (IST, R. Amthauer), Russian modification), Group-Embedded Figures Test (GEFT } \\
\text { Witkin, Oltman, Raskin, Karps), Torrance creativity test, artificial grammar tasks (Reber's paradigm). }\end{array}$} \\
\hline \multicolumn{3}{|c|}{ Informative variables } \\
\hline $\begin{array}{l}\text { 1) Implicit Learning Quotient = 0.45; } \\
\text { 2) Number Series (Subtest 5) - 121; } \\
\text { 3) Sentence Completion (Subtest 1) - 122; } \\
\text { 4) Verbal Analogies (Subtest 2) - 115; } \\
\text { 5) Verbal Originality - 30; } \\
\text { 6) Perception Constructive Activity - 22; }\end{array}$ & $\begin{array}{l}\text { 1) Implicit Learning Quotient = 0.5; } \\
\text { 2) IQ = 118; } \\
\text { 3) Number Series (subtest 5) - 121; } \\
\text { 4) Transformation Stimulus - 45; }\end{array}$ & $\begin{array}{l}\text { 1) Implicit learning quotient = 0.7; } \\
\text { 2) Verbal Similarities (subtest 4) - 126; } \\
\text { 3) Cubes (Subtest 8) - 126; } \\
\text { 4) Verbal Originality - 50; }\end{array}$ \\
\hline
\end{tabular}

The general intelligent and general implicit learning ability are most interesting options in the interval-crossings because these crossings predictive success. You can see from Table 1, the implicit learning takes place through the different professional fields. IQ is general predictor effectiveness in professions high level according all history psychometric. Effect of both parameters was evaluated using Matlab system. Subtractive clustering algorithm was used for understanding the contribution of both parameters to achieve. 
Table 2. Surfaces «input - output» of Sugeno model (Matlab system)

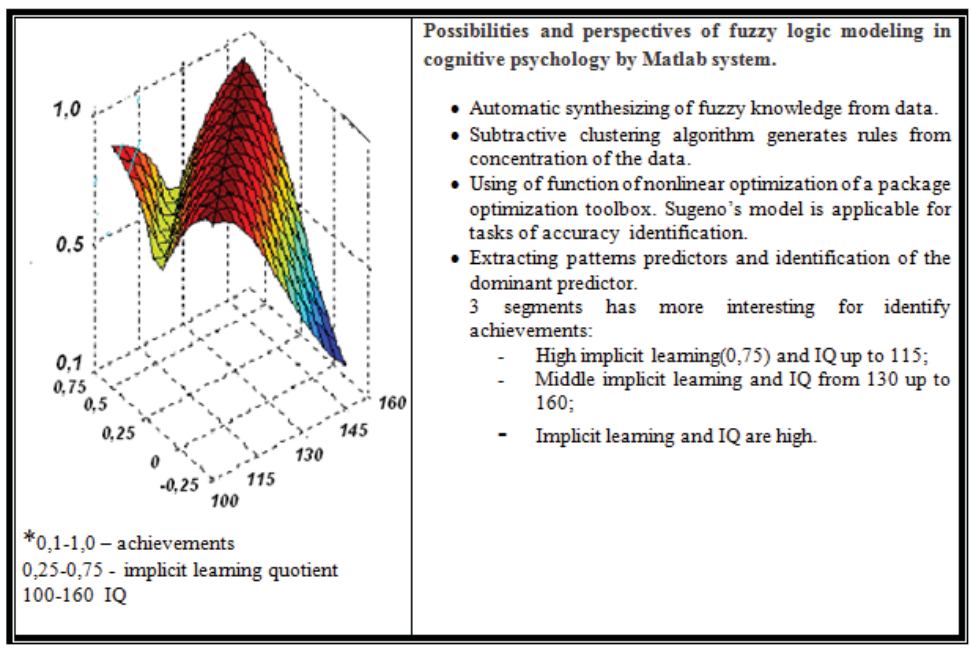

\section{General Conclusion}

On the one hand, modern cognitive psychology has approached the methodological restructuring empirical studies of implicit processes, on the other hand modern philosophical community has approached to the study of implicit cognition as a general mechanisms of intelligence, mind and knowledge increase.

Statistical methods, which new for psychology, such as fuzzy logic, opens new possibilities and perspectives for experimental and empirical models, for change methodology direction and data interpretations.

- the fuzzy logic modeling is perspective forecasting method for identification cognitive predictors of real practical achievements and expert level of professional development;

- the patterns cognitive processes (the interval crossings) are predictors of real practical achievement;

- the implicit learning is a general predictor of professional development success and the achievement of expert level. However implicit learning is more significant predictor for achievements in social professional domains and under middle level IQ.

Implicit learning option is manifested in the ties of cognitive properties of the stable. However, the system provides an implicit learning skills only, while achieving a new level of professional development or acquisition of a new form of effective behavior is provided a compound of implicit learning and general intelligence, it is possible that the knowledge of implicit learning, involvement of metacognitive processes.

\section{Acknowledgement}

The study was supported by the Russian Foundation for the Humanities, project № 12-06-00279 «Cognitive predictors of performance highly skilled labor, economic behavior and socialization of young people."

\section{References}

Bierman, D., Destrebecqz, A., \& Cleeremans, A. (2005) Intuitive decision making in complex situations: Somatic markers in an implicit artificial grammar learning task. Cognitive, Affective, and Behavioral Neuroscience, 5, 297-305.

Boyer, M., Destrebecqz, A. \& Cleeremans, A. (2005).Processing Abstract Sequence Structure: Learning Without Knowing, or Knowing Without Learning? Psychological Research, 69, 383-398.

Chalmers D. (2008). Mind and Consciousness: Five Questions. In (P. Grim, ed) Mind and Consciousness: 5 Questions. Automatic Press.

Cleeremans, A. (2001). Implicit learning and consciousness: An empirical, philosophical and computational consensus (French R). Psychology Press.

Dienes Z. \& Longuet-Higgins Ch., (2004). Can musical transformations be implicitly learned. Cognitive Science, 28, 531-558. 
Gebauer G. F. and Mackintosh N. J. (2007) Psychometric Intelligence Dissociates Implicit and Explicit Learning.II Journal of Experimental Psychology: Learning, Memory, and Cognition, Vol. 33, No. 1, 34-54.

Gobet, F., \& Charness, N. (2006). Chess and games. Cambridge handbook on expertise and expert performance (pp. 523-538). Cambridge, MA: Cambridge University Press. (http://www.cambridge.org/)

Kiesel, A., Kunde W., Pohl C., Bemer M.P., and Hoffmann,J. (2009) Playing chess unconsciously. Journal of Experimental Psychology: Learning, Memory, and Cognition, 35, 292-298.

Kostrikina I.S. (2010) Intelligent, implicit learning, creativity, cognitive style and practical success of younger specialists. 15th European Conference on Personality, Brno Czech Republic. -C.273-274.

Reber, A. S. (1989). Implicit learning and tacit knowledge. Journal of Experimental Psychology - General, 118(3), 219-235.

Rey A, Goldstein; R.M., Perruchet P., Does unconscious thought improve complex decision making? Psychological research 2009;73(3):372-9.

Vygotsky, L. S. (1994). Tool and symbol in child development. In R. van der Veer \&J. Valsiner (Eds.), The Vygotsky reader (pp. 99-174). Cambridge, MA: Blackwell. 